\title{
Elaboration of Sustainable Forest Model for Community Forest Management in Nghe An Province, Vietnam
}

\author{
Tran Xuan Minh and Nguyen Cong Thanh ${ }^{1}$ \\ Institute of Agriculture and Natural Resources, Vinh University, 182 Le Duan, Vinh City 460000, Nghe An, Vietnam \\ ${ }^{1}$ Center for Digital Educational Technology Research, Vinh University, 182 Le Duan, Vinh City 460000, Nghe An, Vietnam \\ E-mail:minhtx@vinhuni.edu.vn
}

\begin{abstract}
The main trend in sustainable forest management is to use the forests to perfectly accomplish their environmental conservation role parallel with supplying forest products to fulfil communities' requirements. However, forests handed over to the local community are commonly found poor and require driving solutions to make them more stable and productive. The question is how to use the forest in sustainable management. The paper presented the methods for estimating forest products and benefits use based on the so-called sustainable forest model. The sustainable forest model is limited to stem number-diameter distribution (N/DBH distribution), which follows probability density functions. Meyer function is opted to be used in this research because it can make a rather good simulation of N/DBH distribution having the shape of decreasing curves. The results showed that the proposed $N / D B H$ distribution of the sustainable forest model of group II and III has $N=$ $276 \cdot e^{-0.096 D} ; N=164 \cdot e^{-0.063 D}$ (respectively). This forest model will help identify the benefit levels to the community, make suitable and straightforward planning of wood exploitation, and reduce the costs by comparing the number of trees of the researched forests with that of the model.
\end{abstract}

Keywords: Diameter distribution, Ideal forests model, Meyer function, Sample forest model, Sustainable forest management

Forestry business practice requires maintaining a certain level of forest sources with the desired structure; this is the principle and an essential condition to assure non-degradation and continuous and better growing of exploited forests. The development of scientific bases for forestry business is necessary to deal with the issues mentioned above. One of the outstanding requirements is to study and propose forest structures and models to support identifying the way to exploit and use forest resources efficiently. The existing researches have so far proposed the "standard forest model" (Linh 2015), "sample forests model" (Dinh 2012), "ideal forests model" (Roth 2004), "oriented forests model" (Quan 2004, Pham 2008), "sustainable forest model" (Bao Huy 2007). These are the models of forests having high productivity and quality with reasonable structures. The current condition of even average and rich natural forests can hardly reach such a mentioned state, the typical characteristics are that the forest structure is disturbed, requiring adjustment to become stable. Forests handed over to the local community are commonly found poor and require driving solutions to make them more stable and productive (Roth 2004). To build up standardized and sustainable models of forests, forest researches in the world during the recent decades have been changing from qualitative to quantitative with a series of probability density functions used by many researchers to simulate the structures and the relationship among quantities in the forest structures
(Aigbe and Omokhua 2014, Lima et al 2017). The standard forest structure is limited to the N/DBH structure (Stem number-diameter distribution), which follows probability density functions. The so-called negative exponential model is frequently used as a standard of comparison for natural and mixed stands managed on a polycyclic cutting system and as an aid in designing cutting schedules in such stands (Due to the ability to represent natural forest stands, negative exponential functions resembling ideal natural forests, similarly providing protection and production functions are prepared for each forest type separately (Roth 2004). However, scientists commonly recognize no perfect model of forests (Wang and Rennolls 2005). Depending on each succession stage, an established forest structure model may exhibit high applicability or is not suitable for the actual forest situation and should be improved accordinglyand the established forest structure model should be flexibly adaptive to the practical forest state. This trend is being applied in this research to build up sustainable forest models with aims to build a sustainable forest structure model to lead the different forest states to achieve higher productivity, ensure biodiversity, and protect and provide firewood for community life.

\section{MATERIAL AND METHODS}

Study area: The study area is a mountainous district located 
in the southwest of Nghe An province, coordinates $19^{\circ} 18^{\prime} 28^{\prime \prime}$ $\mathrm{N} 104^{\circ} 28^{\prime} 36^{\prime \prime} \mathrm{E}$. Nghe An is directly affected by the tropical monsoon climate. The average temperature varies from 23$25^{\circ} \mathrm{C}$; the highest temperature in July: $39-41^{\circ} \mathrm{C}$; the lowest temperature in January: $80 \mathrm{C}$. The average rainfall is 1450 $\mathrm{mm}$ but unevenly distributed in space and time, the rainy season accounting for $80 \%$ of total annual rainfall. The area of community forest in the study area is 62 ha $(17 \%$ of the total forest area). Community forest includes forest state of group II (66.7 \% of the total area of community forest) and forest state of group III (33.3\%), the average $\mathrm{DBH}$ diameter of $14.6 \mathrm{~cm}, 17.7 \mathrm{~cm}$; the average tree height of $10.3 \mathrm{~m}, 13.2$ $\mathrm{m}$; the average stand basal area of $8.25 \mathrm{~m}^{2} \cdot \mathrm{ha}^{-1}, 12.8 \mathrm{~m}^{2} \cdot \mathrm{ha}^{-1}$; the average stand volume of $42.6 \mathrm{~m}^{3} \cdot \mathrm{ha}^{-1}, 84.8 \mathrm{~m}^{3} \cdot \mathrm{ha}^{-1}$ (respectively).

Data collection: Three input variables, namely basal area, diameter-class width, and the number of trees in the respective diameter-classes, are necessary to model stem number-diameter distributions (Roth 2004). The respective data sets have been obtained via forest inventory, using a systematic random sampling design with sample plots of $1000 \mathrm{~m}^{2}$. Fifteen sample plots were chosen, and all trees above $6 \mathrm{~cm}$ diameter were considered for measurement. Tree growth data collected on trees with $\mathrm{DBH} \geq 6 \mathrm{~cm}$ in all sample plots include diameter at breast height (DBH). As far as the ideal stand model is concerned, sample plots have to be located in areas where the present forest condition satisfies the postulation stated above. Thus, rivers, roads, clearings for shifting cultivation, or special edaphic forest formations not representative of the forest type should not be located within the sample plots (Gimaretcarpentier et al 1998).

Methodology: In this research, the sample/sustainable forest structure model is shown in N/DBH distribution having the shape of decreasing curves, "the inverted J-shaped form" (McCarthy and Weetman 2006). Meyer function is opted to be used in this research because it can make a rather good simulation of $\mathrm{N} / \mathrm{DBH}$ distribution having the shape of decreasing curves. The sample forest model having N/DBH distribution following the decreasing rule of Meyer function has the form: $N=\alpha \cdot e^{-\beta . D}$, where $N$ is frequency per hectare in diameter-class; $D$ is the centre of each diameter-classes at breast height; $\mathrm{e}$ is the base of the natural logarithm; $\alpha, \beta$ is estimated regression coefficients. The sustainable forest model with the same shape as the sample forest model has the form: $N=\alpha^{\prime} \cdot e^{-\beta . D}$, with $0<\alpha^{\prime}<\alpha$. The purpose is to find out the reasonable value of $\alpha^{\prime}$.

Elaboration of the sample forest structure model: Regarding each forest state group, the structure of sample plots is developed based on the data collected on the

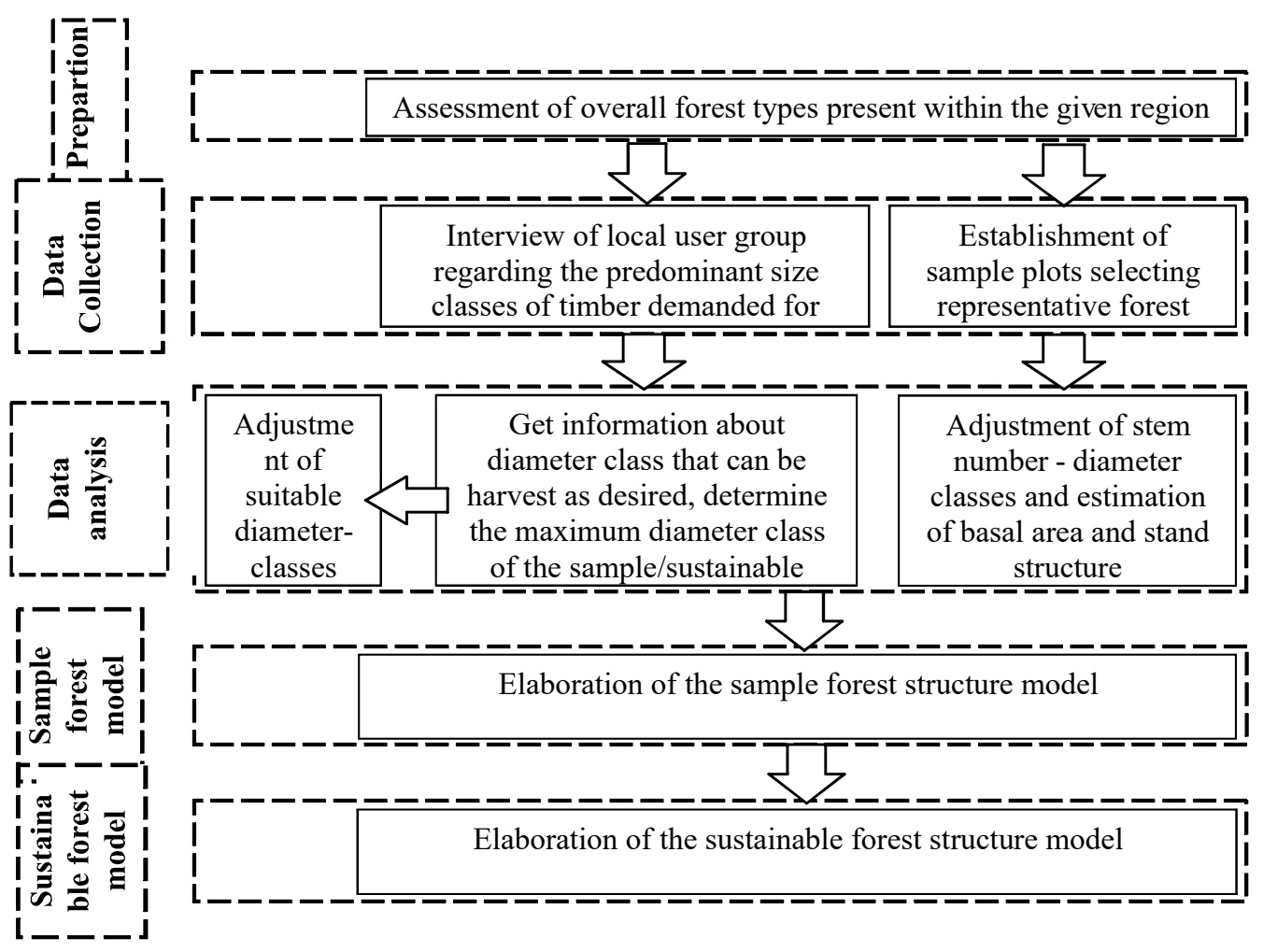

Fig. 1. The sequence of tasks necessary to determine suitable sustainable models for respective forest types 
distribution of trees having diameters of the currently three best sample plots (the largest forest volume). Meyer function is used to manipulate the N/DBH distribution of wood trees having $\geq 6 \mathrm{~cm}$. The result of identifying Meyer function may go in the following two directions:

Direction 1: At least one of the 3 sample plots sees the compliance of empirical N/DBH distribution with theoretical distribution. In this case, the sample plots which is most suitable for the Meyer function will be chosen as the sample forest model.

Direction 2: The empirical N/DBH distribution of all 3 sample plots is not in line with the theoretical N/DBH distribution; this can be explained as due to the disturbance of tree layers' structures. In this case, N/DBH distribution will be manipulated according to Meyer function based on maintaining the number of trees in the upper DBH class and the distribution of tree layers at the reserve/adjacent/mature ratio $=1 / 3 / 5$ (Dinh 2012). This ratio can calculate the starting diameter class of trees required for making the equation. Therefore, the increasing of trees' diameters to manipulate the distribution by Meyer function can increase the compliance of theoretical $N / D B H$ distribution with the empirical $\mathrm{N} / \mathrm{DBH}$ distribution. After selecting the Meyer function, the trees with smaller diameters will be adjusted to align with the theoretical distribution.

Elaboration of the sustainable forest structure model: $A$ sustainable forest model is the one that has the same shape as the sample forest model having the Meyer equation in the form: $N=\alpha^{\prime} \cdot e^{-\beta . D}$

To build up a sustainable forest model, it is required to identify the suitable position of $N / D B H$ curves (or the reasonable value of $\alpha^{\prime}$ ). This value is not necessarily fixed but can be changing within a specific range depending on forest management requirements and utilization. This range is called the 'stability threshold' in this research. The "stability threshold" varies from $\alpha_{1}$ to $\alpha_{2}$ This is the value range that can assure reasonable forest capital for forest regeneration and development. The 'stability threshold' can be identified. The stability threshold is identified based on the changing range of forest volume. The forest volume's changing range is from $\left(M_{1}, G_{1}\right)$ to $\left(M_{2}, G_{2}\right)$ with $M_{1}, G_{1}$ being the minimum volume and the minimum basal area of sample plots of each forest state; $\mathrm{M}_{2}, \mathrm{G}_{2}$ being the maximum volume and the maximum basal area of sample plots of each forest state. The value $\alpha$ of the Meyer equation of the sample forest model will be changed until: (1) The volume of theoretical forests reach the value of $\left(\mathrm{M}_{1}, \mathrm{G}_{1}\right)$ and then $\alpha=\alpha_{D} ;(2)$. The volume of theoretical forest model reaches the value of $\left(\mathrm{M}_{2}, \mathrm{G}_{2}\right)$ and then $\alpha=\alpha_{T}$. The value $\alpha_{T}$ is taken as the upper value of the stability threshold $\alpha_{2}=\alpha_{T}$.

The lower value $\alpha_{1}$ of the stability threshold is identified by $\alpha_{1}=\max \left(\alpha_{D}, \alpha_{K T}\right)$, where: $\alpha_{D}$ is the value which forests reach the lower limit of the changing range of its volume. As $\alpha_{D}$ is the value calculated for forest states having the lowest volume, so $\alpha_{1}>\alpha_{D}$. $\alpha_{K T}$ is the value in which the largest adjustment of existing forests to stable forests ensures logging intensity (logging intensity is based on regulation 40/QĐ-BNN-2005 for the broadleaf forest, semi-deciduous forest: is allowed to exploit forests but not lower than the limit of $35 \%$ of the volume). The sustainable forest model can be simulated in the equation: $N=\alpha^{\prime} \cdot e^{-\beta . D}$, with $\alpha^{\prime}$ being in the range $\left(\alpha_{1}, \alpha_{2}\right)$. In this research, value $\alpha^{\prime}$ is proposed to set up a sustainable forest model and must satisfy two requirements:

- $\alpha^{\prime}$ must be within the stability threshold $\left(\alpha_{1}, \alpha_{2}\right)$.

- $\alpha$ ' must satisfy the requirement that forest volume must not be less than the current average level. Based on the value $\alpha_{\mathrm{TB}}$ at which forests reach the average volume level, we have $\alpha^{\prime} \geq \alpha_{T B}$. Depending on the good or bad state of forests, $\alpha_{1}$ may be bigger or smaller than $\alpha_{T B}$; in other words, $\alpha_{T B}$ may be within or out of the stability threshold.

As such, a sustainable forest model should have $\alpha^{\prime}$ satisfying: $\alpha^{\prime}=\max \left(\alpha_{1}, \alpha_{T B}\right)$. This is not the best value but only the value assuring forest stability; this value can be gradually upgraded and fixed at a suitable level within the stability threshold, depending on forest states and management targets.

\section{RESULTS AND DISCUSSION}

Sample forest model of forest state of group II: Three best sample plots of group II have been chosen to manipulate $\mathrm{N} / \mathrm{DBH}$ distribution by Meyer exponential function (Table 1). In all 3 sample plots, the Meyer function has a very high correlation coefficient $(R>0.95)$. However, existence of Meyer function $(\mathrm{N} / \mathrm{DBH})$ distribution having diameter bigger than 6 only one sample (plot No. 9). This is also the sample plot selected as the sample forest model for group II. Although the remaining 2 sample plots have $N / D B H$

Table 1. Meyer equation of sample forest model of group II

\begin{tabular}{lcccccc}
\hline Sample plot No & Volume $\left(\mathrm{m}^{3} \mathrm{ha}^{-1}\right)$ & Equation & $R$ & $X^{2}$ calculated & $X^{2}$ test & Conclusion \\
\hline 9 & 73.632 & $N=439.058 \cdot \mathrm{e}^{-0.096 D}$ & 0.992 & 7.71 & 15.51 & Passed \\
7 & 48.625 & $N=365.622 \cdot \mathrm{e}^{-0.095 D}$ & 0.976 & 20.88 & 9.49 & Types \\
2 & 44.109 & $N=422.569 \cdot \mathrm{e}^{-0.106 D}$ & 0.981 & 29.44 & 11.1 & Types \\
\hline
\end{tabular}


structures which cannot assure the existence of Meyer function, and can observe that the gap of $x^{2}$-calculated and $X^{2}$-test is minor and this means that forests of group II all have $\mathrm{N} / \mathrm{DBH}$ distribution asymptotic (nearly suitable) to the decreasing rules of Meyer function.

The forest state of group II having N/DBH distribution following the decreasing rule of Mayer function have the following equation: $N=439.058 \cdot \mathrm{e}^{-0.0960}$; and is also the existing equation that has the highest correlation coefficient: $R=0.992$ (Table 1). In the selected pattern, the Meyer function makes a perfect simulation of empirical $\mathrm{N} / \mathrm{DBH}$ distribution. The gap between the empirical and theoretical number of trees of each diameter-classes is minor. Three best sample plots of forest state of group III have been chosen to describe N/DBH distribution with Meyer exponential function (Table 2).

Sample forest model of forest state of group III: The three best sample plots simulated by Meyer function are listed in Table 3. The N/DBH distribution of 2 sample plots cannot satisfy the equation's existence, the gap between $x^{2}$ calculated and $X^{2}$-test is rather significant and confirms that there is no compliance with the Meyer function when describing the empirical $\mathrm{N} / \mathrm{DBH}$ distribution of these 2 sample plots. This has proven that the disturbance of the $\mathrm{N} / \mathrm{DBH}$ structure of the best forests in group III is better than that of group II's best forests. The natural forests are reaching a better and better state, and the natural elimination process will gradually make $\mathrm{N} / \mathrm{DBH}$ structures change to a more stable state with the succession of tree layers gradually reaching stability (Leiva et al 2012, Carretero and Alvarez 2013). The sample forest model of group III with N/DBH distribution following the decreasing rule of Meyer function has the equation: $N=253.339 \cdot \mathrm{e}^{-0.0630}$; this is also the existing equation that has the highest correlation coefficient: $R=$ 0.990 (Table 3).

The distribution results of 610 trees (forest state of group II) and 644 trees (forest state of group III) in the empirical diameter classes and their evaluation with Meyer probability function at $4 \mathrm{~cm}$ DBH class interval and empirical $\mathrm{DBH}$ frequencies shows that there are more trees in the lower $\mathrm{DBH}$ classes than in the upper DBH classes( Tables 2 and 4). This pattern indicates more trees in the lower $\mathrm{DBH}$ class that is sufficient to replace trees in the upper $\mathrm{DBH}$ class in the future (i.e. when the big trees are harvested or when they die). This is consistent with previous reports for two other tropical rainforests (Boubli et al 2004, Bobo et al 2006). The implication of this is that the forests are still undergoing regeneration and recruitment, which are vital indicators of forest health and vigour (Jimoh et al 2012). N/DBH distribution illustrates the balanced state among regeneration, growth, development, and natural elimination, assuring the succession of forest tree generation, creating the stability of forest stand output, and helping calculate the number of trees in each diameter-class for planning silviculture treatment (Leiva et al 2012, Carretero and Alvarez 2013). Information on the current diameter distribution of a forest stand can be used to indicate whether the density of smaller trees in a stand is sufficient to replace the current population of larger trees (Rubin et al 2006, Aigbe and Omokhua 2014) and allows prediction of its future structure, which provides even better supporting sustainable forest management (Podlaski 2006, 2008).

Sustainable forest model for forest state of group II: A sample forest model is the one that has the best forest state and assures the success of diameter classes and also illustrates forest tree generations' succession by having a

Table 2. Empirical and theoretical N/DBH distribution of forest state of group II

\begin{tabular}{lcccccccccccc}
\hline Diameter size-class $(\mathrm{cm})$ & 8 & 12 & 16 & 20 & 24 & 28 & 32 & 36 & 40 & 44 & 48 & 52 \\
Empirical frequency & 197 & 117 & 90 & 63 & 47 & 33 & 27 & 17 & 10 & 7 & 3 & 3 \\
Theoretical frequency & 204 & 139 & 95 & 64 & 44 & 30 & 21 & 14 & 9 & 6 & 4 & 3 \\
\hline
\end{tabular}

Table 3. Mayer equation of sample forest model of group III

\begin{tabular}{lcccccc}
\hline Sample plot No & Volume $\left(\mathrm{m}^{3} \mathrm{ha}^{-1}\right)$ & Equation & $R$ & $X^{2}$ calculated & $X^{2}$ test & Conclusion \\
\hline 5 & 131.859 & $N=253.339 \cdot \mathrm{e}^{-0.0630}$ & 0.990 & 7.67 & 16.92 & Passed \\
4 & 84.68 & $N=220.476 \cdot \mathrm{e}^{-0.0710}$ & 0.975 & 81.77 & 16.92 & Types \\
3 & 80.958 & $N=254.944 \cdot \mathrm{e}^{-0.0780}$ & 0.968 & 59.58 & 15.51 & Types \\
\hline
\end{tabular}

Table 4. Empirical and theoretical N/DBH distribution of forest state of group III

\begin{tabular}{lcccccccccccc}
\hline Diameter size-class $(\mathrm{cm})$ & 8 & 12 & 16 & 20 & 24 & 28 & 32 & 36 & 40 & 44 & 48 & 52 \\
\hline Empirical frequency & 160 & 100 & 87 & 67 & 60 & 47 & 37 & 33 & 20 & 13 & 10 & 10 \\
Theoretical frequency & 153 & 119 & 92 & 72 & 56 & 43 & 34 & 26 & 20 & 16 & 12 & 10 \\
\hline
\end{tabular}


similar shape to the sample model. The N/DBH distribution curve of the sustainable forest model has a similar shape and is lower than the sample forest model's N/DBH distribution curve. The issue is to find out the suitable position of the N/DBH curve to assure stability and required to lower value $\alpha$ of the equation simulating $N / D B H$ distribution of sample forests $\left(N=\alpha \cdot e^{-\beta . D}\right)$ to a reasonable value $\left(\alpha^{\prime}\right)$. That rationality is decided with reasonable forest volume to assure the output (or total basal area) and the number of regenerated trees. The results of identifying the stability threshold and the reasonable value $\alpha$ ' of the sustainable forest model of group II and N/DBH distribution in line with the changes of value $\alpha$ (Table 6). According to Table 5.

$\alpha_{1}=\max \left(\alpha_{D}, \alpha_{K T}\right)=276, \alpha_{2}=\alpha_{T}=426, \alpha_{1}=\alpha_{K T} \leq \alpha^{\prime}<\alpha_{2}, \alpha^{\prime}=$ $\max \left(\alpha_{T B}, \alpha_{K T}\right)$, As $\alpha_{T B}<\alpha_{K T}$, then $\alpha^{\prime}=\alpha_{K T}=276$

As such, the stability threshold of the forest model of group II is within (276; 426). Value $\alpha$ ' of the sustainable forest model proposed for forest group II is 276 . The lowering the values of the $N / D B H$ distribution curve of sample forest model of group II to $\alpha_{T B}$ and $\alpha_{K T}, N / D B H$ distributions are similar: $N \alpha_{T B} \approx N \alpha_{K T}$ (Table 6). At the same time, can observe that $\alpha_{T B}<\alpha_{K T}$, means that the calculated average volume of forests of group II has not reached a stable level. The sustainable forest model of group II has quantitative indicators within the following stable range (Table 6). Then $\mathrm{N} / \mathrm{DBH}$ distribution of sample forest model of group II has the form: $N=439.058 \cdot \mathrm{e}^{-0.096 D}$. The proposed $N / D B H$ distribution of the sustainable forest model of group II has the form: $N=$ $276 \cdot e^{-0.096 D}$. This is only the suggested sustainable forest model. Depending on the forest business and management strategy, a suitable value of $\alpha^{\prime}$ can be fixed in each specific condition. If the target is to make maximum exploitation of forests to meet the current wood demand of the society, we can set $\alpha^{\prime}$ at the minimum level. On the contrary, if like to protect forests and increase forest reserves, can increase the value of $\alpha^{\prime}$. Obviously, $\alpha^{\prime}$ must always stay within the stable range to assure that the sustainable forest model can illustrate or guarantee the feasibility of driving current forest states to a steady state. The comparison of the sample forest model and sustainable forest model is shown in (Fig. 3).

Sustainable forest model of forest state of group III; The results of identifying the stability threshold and value $\alpha^{\prime}$ of the sustainable forest model of group III and N/DBH distribution

Table 6. Indicators of sustainable forest model and forest models within the stability threshold of group II

\begin{tabular}{lccc}
\hline Quantitative indicators & $\begin{array}{c}\text { Lower } \\
\text { stable } \\
\text { values }\end{array}$ & $\begin{array}{c}\text { Upper } \\
\text { stable } \\
\text { values }\end{array}$ & $\begin{array}{c}\text { Proposed values } \\
\text { for sustainable } \\
\text { forest model }\end{array}$ \\
\hline $\begin{array}{l}\text { Stem number with } \mathrm{DBH} \geq \\
6 \mathrm{~cm} \text {, trees ha }\end{array}$ & 814 & 1256 & 814 \\
$\begin{array}{l}\text { Number of regenerating } \\
\text { trees, trees ha }\end{array}$ & 416 & 642 & 416 \\
$\begin{array}{l}\text { Stand basal area, } \mathrm{m}^{2} \mathrm{ha}^{-1} \\
\text { Stand volume, } \mathrm{m}^{3} \mathrm{ha}^{-1}\end{array}$ & 8.2 & 12.7 & 8.2 \\
\hline
\end{tabular}

Table 5. N/DBH distribution of forest state of group II corresponds to the changing of value $\alpha$

\begin{tabular}{|c|c|c|c|c|c|}
\hline Diameter size-class (cm) & $\begin{array}{c}N \alpha_{L T}, \text { trees } \mathrm{ha}^{-1} \\
\alpha=439.058\end{array}$ & $\begin{array}{c}N \alpha_{D}, \text { trees } \mathrm{ha}^{-1} \\
\alpha_{D}=158\end{array}$ & $\begin{array}{c}N \alpha_{T B}, \text { trees } \mathrm{ha}^{-1} \\
\alpha_{T B}=246\end{array}$ & $\begin{array}{c}N \alpha_{K T}, \text { trees } \mathrm{ha}^{-1} \\
\alpha_{K T}=276\end{array}$ & $\begin{array}{c}N \alpha_{T} \text {, trees } \mathrm{ha}^{-1} \\
\alpha_{T}=426\end{array}$ \\
\hline 2 & 362 & 130 & 203 & 228 & 352 \\
\hline 4 & 299 & 108 & 168 & 188 & 290 \\
\hline 8 & 204 & 73 & 114 & 128 & 198 \\
\hline 12 & 139 & 50 & 78 & 87 & 135 \\
\hline 16 & 94 & 34 & 53 & 59 & 92 \\
\hline 20 & 64 & 23 & 36 & 40 & 62 \\
\hline 24 & 44 & 16 & 25 & 28 & 43 \\
\hline 28 & 30 & 11 & 17 & 19 & 29 \\
\hline 32 & 20 & 7 & 11 & 13 & 20 \\
\hline 36 & 14 & 5 & 8 & 9 & 13 \\
\hline 40 & 9 & 3 & 5 & 6 & 9 \\
\hline 44 & 6 & 2 & 4 & 4 & 6 \\
\hline 48 & 4 & 2 & 2 & 3 & 4 \\
\hline 52 & 3 & 1 & 2 & 2 & 3 \\
\hline Total & 1292 & 465 & 726 & 814 & 1256 \\
\hline
\end{tabular}

$N \alpha_{L T}, N \alpha_{D}, N \alpha_{T B}, N \alpha_{K T}, N \alpha_{T}$ is frequency per hectare in diameter-class. $\alpha$ is the value of the Meyer equation of the sample forest model; $\alpha_{D}$ is the value which forests reach the lower limit of the changing range of its volume; $\alpha_{T B}$ is the value which forests reach the average volume level; $\alpha_{K T}$ is the value in which the largest adjustment of existing forests to stable forests ensures logging intensity; $\alpha_{T}$ is the value which forests reach the upper limit of the changing range of its volume. 
with changing values of $\alpha$ are given in Table 7 .

According to Table 7: $\alpha_{1}=\max \left(\alpha_{D}, \alpha_{K T}\right)=164, \alpha_{2}=\alpha_{\mathrm{T}}=$ 253.339, $\alpha_{1}=\alpha_{K T} \leq \alpha^{\prime}<\alpha_{2}, \alpha^{\prime}=\max \left(\alpha_{T B}, \alpha_{K T}\right)$

As $\alpha_{T B}<\alpha_{K T}$, then $\alpha^{\prime}=\alpha_{K T}=164$

Therefore, the stability threshold of the forest model of group III is within $(164 ; 253)$. The value of $\alpha^{\prime}$ of the sustainable forest model proposed for forest group III is 164 . The $\alpha_{T B}$ and $\alpha_{K T}$ are approximately equal; this means that if the average volume of the forest of group III is calculated, such results may reach the lower values of the stability threshold. Thus, the feasibility of driving forests of group III to their stable level is rather high.

The suggested stability threshold and sustainable forest

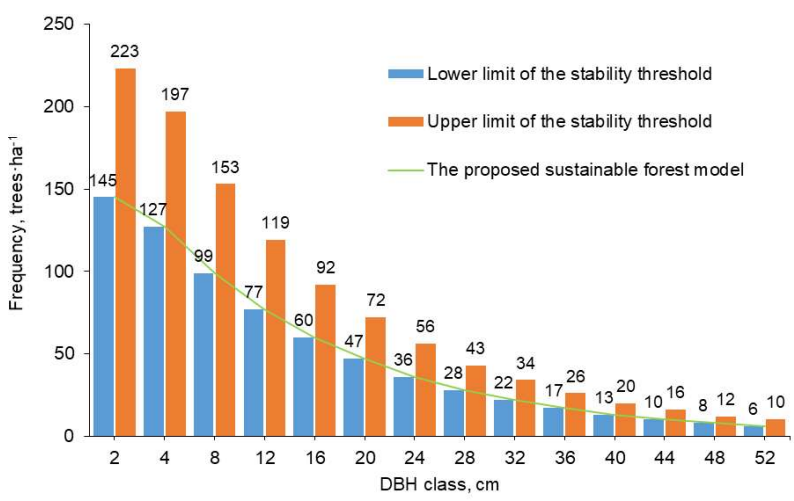

Fig. 2. Stability threshold and sustainable forest model have been proposed for the forest state of group II model are shown in Figure 4. Then N/DBH distribution of the sample forest model of group III has the form: $N=253.339 \cdot e^{-}$

Table 8. Indicators of sustainable forest model and forest models within the stability threshold of group III

\begin{tabular}{lccc}
\hline Quantitative indicators & $\begin{array}{c}\text { Lower } \\
\text { stable } \\
\text { values }\end{array}$ & $\begin{array}{c}\text { Upper } \\
\text { stable } \\
\text { values }\end{array}$ & $\begin{array}{c}\text { Proposed values } \\
\text { for sustainable } \\
\text { forest model }\end{array}$ \\
\hline $\begin{array}{l}\text { Stem number with } \mathrm{DBH} \geq 6 \mathrm{~cm}, \\
\text { trees ha }\end{array}$ & 695 & 1073 & 695 \\
$\begin{array}{l}\text { Number of regenerating trees, } \\
\text { trees ha- }\end{array}$ & 272 & 420 & 272 \\
$\begin{array}{l}\text { Stand basal area, } \mathrm{m}^{2} \mathrm{ha}^{-1} \\
\text { Stand volume, } \mathrm{m}^{3} \mathrm{ha}^{-1}\end{array}$ & 12.46 & 19.2 & 12.46 \\
\hline
\end{tabular}

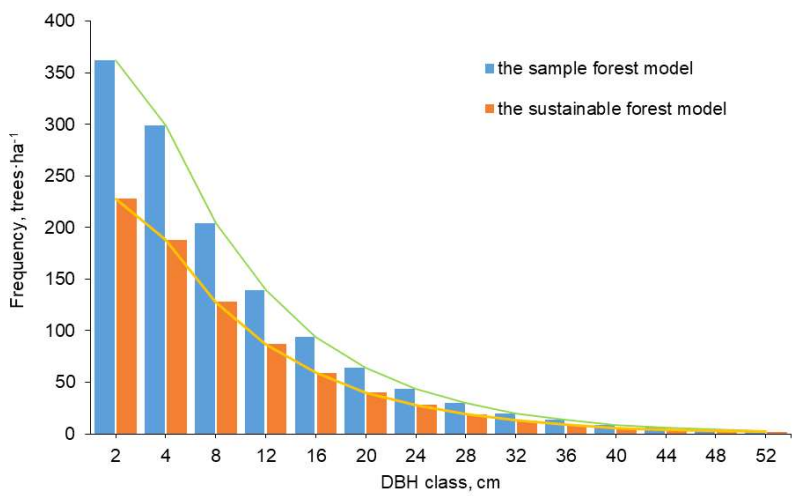

Fig. 3. N/DBH distribution of sample forest model and sustainable forest model of group II

Table 7. N/DBH distribution of the forest state of group III corresponds to the changing of values $\alpha$

\begin{tabular}{|c|c|c|c|c|c|}
\hline \multirow[t]{2}{*}{ Diameter size-class $(\mathrm{cm})$} & $N \alpha_{L T}$, trees $\mathrm{ha}^{-1}$ & $N \alpha_{D}$, trees ha $^{-1}$ & $N \alpha_{T B}$, trees ha ${ }^{-1}$ & $N \alpha_{K T}$, trees ha ${ }^{-1}$ & $N \alpha_{T}$, trees ha \\
\hline & $\alpha=253.339$ & $\alpha_{D}=102$ & $\alpha_{T B}=162$ & $\alpha_{K T}=164$ & $\alpha_{T}=253.3$ \\
\hline 2 & 223 & 90 & 143 & 145 & 223 \\
\hline 4 & 197 & 79 & 126 & 127 & 197 \\
\hline 8 & 153 & 62 & 98 & 99 & 153 \\
\hline 12 & 119 & 48 & 76 & 77 & 119 \\
\hline 16 & 92 & 37 & 59 & 60 & 92 \\
\hline 20 & 72 & 29 & 46 & 47 & 72 \\
\hline 24 & 56 & 22 & 36 & 36 & 56 \\
\hline 28 & 43 & 17 & 28 & 28 & 43 \\
\hline 32 & 34 & 14 & 22 & 22 & 34 \\
\hline 36 & 26 & 11 & 17 & 17 & 26 \\
\hline 40 & 20 & 8 & 13 & 13 & 20 \\
\hline 44 & 16 & 6 & 10 & 10 & 16 \\
\hline 48 & 12 & 5 & 8 & 8 & 12 \\
\hline 52 & 10 & 4 & 6 & 6 & 10 \\
\hline Total & 1073 & 432 & 688 & 695 & 1073 \\
\hline
\end{tabular}

$\mathrm{Na} \quad \mathrm{Na} \quad \mathrm{Na} \quad \mathrm{Na} \quad \mathrm{N \alpha}$ is frequency per hectare in diameter-class. $\alpha$ is the value of the Meyer equation of the sample forest model; $\alpha_{0}$ is the value which forests reach the lower limit of the changing range of its volume; $\alpha_{T B}$ is the value which forests reach the average volume level; $\alpha_{K T}$ is the value in which the largest adjustment of existing forests to stable forests ensures logging intensity; $\alpha_{T}$ is the value which forests reach the upper limit of the changing range of its volume. 


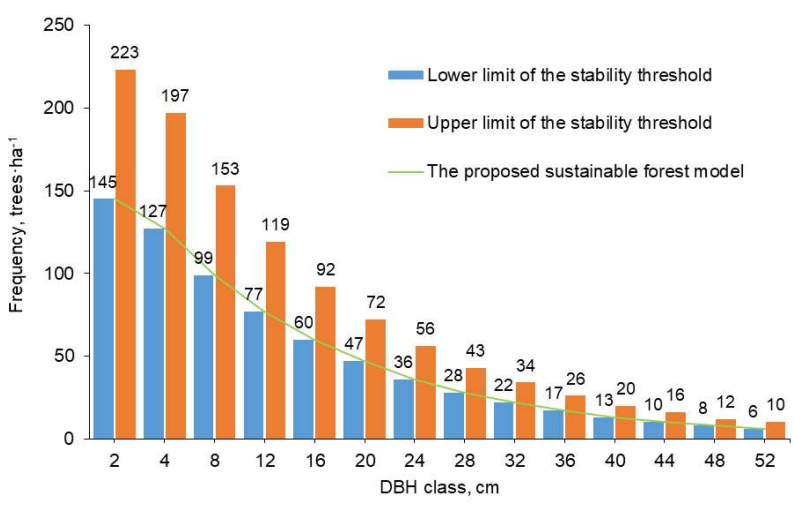

Fig. 4. Suggested stability threshold and sustainable forest model for forest state of group III

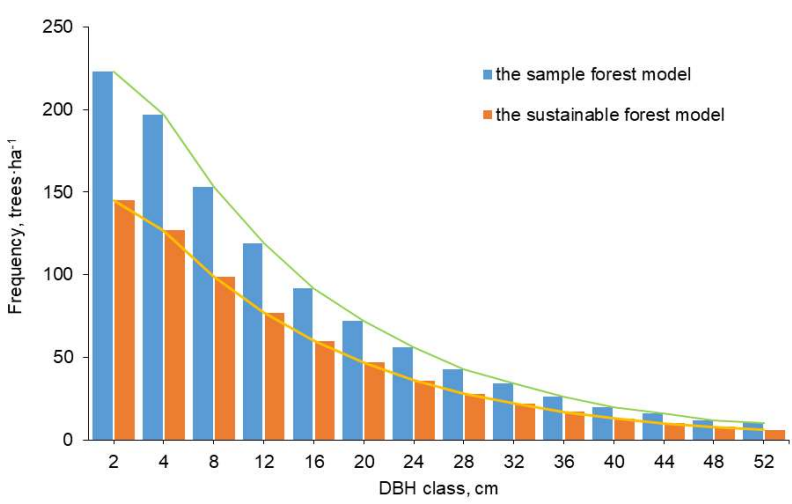

Fig. 5. N/DBH distribution of sample models and sustainable models for forest state of group III

${ }^{0.0630}$. The proposed N/DBH distribution of the sustainable forest model of group III has the form: $N=164 \cdot e^{-0.063 D}$. This forest model is suggestive only. Depending on the forest business and management strategy, a suitable value of $\alpha^{\prime}$ can be fixed in each specific condition. The comparison of the sample forest model and sustainable forest model is shown in (Fig. 5). The decreasing speed or the slope of the curve of N/DBH distribution shows the advantage of site potentials (Fig. 3,5). The practice has proven that the structure of forests of group II tends to be more disturbance than that of the forest of group III. The slope of the curve of N/DBH distribution of forest of group III is also less downward than that of the forest of group II because forests are reaching better and better state with the time towards stability.

\section{CONCLUSION}

The sustainable forest model will help identify the benefit levels to the community and make suitable and straightforward planning of wood exploitation, reduce the costs through comparing the number of trees of the researched forests with that of the model. The number of trees exceeding that of the model is the part that can be exploited .The number of shortage trees of each diameter size needs to be maintained and forest nourishment to reach a stable level. The sustainable forest model is a tool that helps us to manage and monitors handed over forests, meeting requirements of maintaining a sufficient number of trees with minimum diameter size-classes equivalent to that of a sustainable forest model. The task can be simply undertaken by supervising the number of trees according to required diameter size classes, which can be favorably done by management authorities and the people. According to prevailing regulations, only forest plots that have reached volume standards can be exploited. This has caused a massive obstacle due to long waiting times. Besides, it is difficult for people to be aware of exploitable forest standards. At the same time, if the number of trees with various diameter size-classes of the current forest state is compared with that of a sustainable forest model and even in young and poor forest conditions, a certain number of trees of various diameter size-classes can still be exploited to meet community demand, which can concurrently adjust such forests to a stable state with better productivity and efficiency. When comparing the sustainable forest model with the current forest plots, the community may have more opportunities to improve their knowledge of their forest plots, based on which they can not only identify the number of trees to be exploited and cultivated but also have discussions to find out suitable forest management measures given available resources.

\section{REFERENCES}

Aigbe $\mathrm{HI}$ and Omokhua GE 2014. Modelling diameter distribution of the tropical rainforest in Oban forest reserve. Journal of Environment and Ecology 5(2): 130-143.

Bao Huy 2007. Application of sustainable forest model into community forest management oriented towards sustainable utilization of natural forest resources. Vietnam Journal of Agriculture and Rural Development 106(2): 37-43 (in Vietnamese).

Bobo KS, Waltert M, Sainge M, Njokagbor J, Fermon $H$ and Mühlenberg M 2006. From forest to farmland: Species richness patterns of trees and understorey plants along a gradient of forest conversion in Southwestern Cameroon. Biodiversity and Conservation 15: 4097-4117.

Boubli JP, Eriksson J, Wich S, Hohmann G and Fruth B 2004. Mesoscale transect sampling of trees in the lomako-yekokora interfluvium, Democratic Republic of the Congo. Biodiversity and Conservation 13: 2399-2417.

Carretero AC and Alvarez ET 2013. Modelling diameter distributions of Quercus suber L. stands in "Los Alcornocales" Natural Park (Cádiz-Málaga, Spain) by using the two parameter Weibull functions. Forest Systems 22(1): 15-24.

Dinh VD 2012. Research on the scientific basis of natural forest management in Con Cuong SFE, Nghe An province. Ph.D. Dissertation, Forest University, Vietnam, p 210 (in Vietnamese).

Gadow K and Hui G 1999. Modelling forest development, Forestry Sciences, Springer Netherlands, Dordrecht. p 213.

Gimaretcarpentier C, Pelissier R, Pascal JP and Houllier F 1998. 
Sampling strategies for the assessment of tree species diversity. Journal of Vegetation Science 9(2): 61-172.

Jimoh SO, Adesoye PO, Adeyemi AA and Ikyaagba ET 2012. Forest structure analysis in the Oban Division of Cross River National Park, Nigeria. Journal of Agricultural Science and Technology 2: 510-518.

Leiva V, Ponce GM, Marchant C and Bustos O 2012. Fatigue statistical distributions useful for modeling diameter and mortality of trees. Revista Colombiana de Estadística 35: 349-370.

Lima RBD, Bufalino L, Alves junior FT, Silva JAAD and Ferreira RLC 2017). Diameter distribution in a Brazilian tropical dry forest domain: predictions for the stand and species. Annals of the Brazilian Academy of Sciences 89(2): 1189-1203.

Linh VB 2015. Forest structure in the development and use of forest capital. Vietnam Journal of Forest 3: 2-6 (in Vietnamese).

McCarthy JW and Weetman G 2006. Age and size structure of gapdynamic, old-growth boreal forest stands in Newfoundland. Silva Fennica 40(2): 209-230.

Podlaski R 2006. Suitability of the selected statistical distribution for fitting diameter data in distinguished development stages and phases of near-natural mixed forests in the Swietokrzyski National Park (Poland). Forest Ecology and Management 236:

Received 21 October, 2021; Accepted 28 December, 2021
393-402.

Podlaski R 2008. Characterization of diameter distribution data in near-natural forests using the Birnbaum-Saunders distribution. Canadian Journal of Forest Research 18: 518-527.

Pham VT 2008. Proposing oriented forest structure models in some provinces of North Central Coast and Central Highlands. Master Dissertation, Forest University, Vietnam, p 150 (in Vietnamese).

Philip MS 1994. Measuring Trees and Forests, Second Edition, Wallingford, Oxon, UK: CAB International, p 310.

Quan NH 2004. Silvicultural system for sustainable forest management. Consultant Report for Social Forestry Development Project, Song Da, p 150 (in Vietnamese).

Roth $\mathrm{P}$ 2004. Elaboration of ideal forest models for the promotion of CBFM in Dak Lak province. Case Study Report, Rural Development Dak Lak-RDDL, p 16.

Rubin BD, Manion PD and Don FL 2006. Diameter distributions and structural sustainability in forests. Forest Ecology and Management 222: 427-438.

Wang M and Rennolls K 2005. Tree diameter distribution modelling: introducing the logit-logistic distribution. Canadian Journal of Forest Research 35(6): 1305-1313. 